\title{
Assessing malaria risk at night-time venues in a low-transmission setting: a time-location sampling study in Zambezi, Namibia
}

Jerry O. Jacobson ${ }^{1}$, Jennifer L. Smith ${ }^{1}$, Carmen Cueto ${ }^{1}$, Mukosha Chisenga ${ }^{2}$, Kathryn Roberts' Michelle Hsiang ${ }^{1,3,4}$, Roly Gosling ${ }^{1}$, Davis Mumbengegwi ${ }^{2}$ and Adam Bennett ${ }^{1 *}$ (D)

\begin{abstract}
Background: Identifying efficient and effective strategies to reach and monitor populations at greatest risk of malaria in low-transmission settings is a key challenge for malaria elimination. In Namibia's Zambezi Region, transmission is ongoing yet its drivers remain poorly understood. A growing literature suggests that night-time social activities may lead to malaria exposure that is beyond the reach of conventional preventive interventions, such as insecticide treated bed nets and indoor residual spraying.
\end{abstract}

Methods: Formative research was conducted with community members in March, 2015 in the catchment areas of six randomly selected health facilities in the western Zambezi Region to identify night-time locations where large numbers of individuals regularly congregate. Using time-location sampling, a survey was conducted between March and May, 2015 at community-identified venues (bars and evening church services) to develop representative estimates of the prevalence of parasite infection and risk factors among venue-goers.

Results: When compared to a contemporaneous household survey of the general population aged 15 and older $(\mathrm{N}=1160)$, venue-goers $(\mathrm{N}=480)$ were more likely to have spent the night away from their home recently $(17.3 \%$ vs. $8.9 \%, P=0.008)$, report recent fever $(65.2 \%$ vs. $36.9 \%, P<0.001)$, and were less likely to have sought care for fever ( $37.9 \%$ vs. $52.1 \%, P=0.011$ ). Venue-goers had higher, but not significantly different, rates of malaria infection (4.7\% vs. $2.8 \%, P=0.740$ ). Risk factors for malaria infection among venue-goers could not be determined due to the small number of infections identified, however self-reported fever was positively associated with outdoor livelihood activities (adjusted odds ratio $[A O R]=1.9,95 \% \mathrm{Cl} 1.0-3.3$ ), not wearing protective measures at the time of the survey ( $A O R=6.8,9 \% \mathrm{Cl} 1.4-33.6)$ and having been bothered by mosquitos at the venue ( $\mathrm{AOR}=2.7,95 \% \mathrm{Cl} 1.5-4)$.

Conclusions: Prevention measures and continued surveillance at night-time venues may be a useful complement to existing malaria elimination efforts.

Keywords: Malaria, Surveillance, Time-location sampling, High-risk populations, Namibia

\footnotetext{
*Correspondence: Adam.Bennett@ucsf.edu

${ }^{1}$ Malaria Elimination Initiative, Global Health Group, University

of California, San Francisco, 550 16th St., San Francisco, CA 94158, USA

Full list of author information is available at the end of the article
} 


\section{Background}

Namibia is a country with low malaria transmission that has successfully reduced the burden of malaria over the past 15 years through the large-scale deployment of longlasting insecticide-treated nets (LLINs), indoor residual spraying (IRS), artemisinin-based combination therapy (ACT), and improved availability of rapid diagnostic tests (RDTs) [1, 2]. Malaria cases and deaths decreased by 98 percent over this period, far surpassing targets and enabling the implementation of elimination strategies.

Although Namibia aims to eliminate malaria by 2022, recent successes have plateaued, with outbreaks commonplace over the past 2 years. Transmission is known to be clustered in the northern regions of the country [1, $3]$, but evidence of the specific drivers of remaining transmission and how to address them would help guide elimination efforts. Lower transmission settings like northern Namibia present unique challenges for surveillance given the small number of infected individuals and increased heterogeneity of transmission both spatially and socially. In some malaria elimination settings, outdoor social and occupational behaviours are thought to lead to increased risk by increasing vector contact outside the home [3-5], thus reducing the effectiveness of household-based preventive interventions, such as IRS and LLINs.

Identifying the circumstances and behaviours that lead to increased risk of infection, as well as how to effectively reach subgroups at increased risk, is essential to reduce malaria transmission. Using time-location sampling (TLS), this study investigated whether locations where individuals tend to gather away from their homes during mosquito-biting hours could prove useful sites to conduct active surveillance and prevention activities in the Zambezi Region. TLS is a multi-stage cluster sampling method in which individuals are recruited from randomly selected venues during randomly selected venue-daytime intervals (VDTs), in order to develop representative estimates of the prevalence of malaria, risk behaviours and prevention uptake among venue-goers $[6,7]$. TLS is frequently used in surveillance of populations at elevated risk for HIV [8]. A similar form of venue-based sampling (without randomization of times) identified excess malaria risk among seasonal migrant agricultural workers in Ethiopia [9].

\section{Methods}

\section{Study site}

This study was conducted in six randomly selected health facility catchment areas (HFCAs), out of 13 total HFCAs in the western Zambezi Region in northeastern Namibia. The Zambezi Region is arid and sparsely populated and borders Zambia and Angola to the north and Botswana to the south. Malaria transmission is seasonal, peaks between December and April and is highly dependent on rainfall patterns. This study was conducted in the western Zambezi Region, where prevalence is highest and access to services lowest. The population was 35,381 based on 2011 census data [10] and the annual parasite index was 26 per 1000 persons in 2014, according to health information system data and a census conducted by the project partners.

The study was conducted simultaneously with a representative household survey in the same catchment areas [11], a facility-based case-control study (Smith et al. [12], pers.commun.), and a peer-referral study to examine clustering of malaria risk within social networks.

\section{Formative assessment}

A formative assessment was conducted in March, 2015 to identify types of venues that were active between dusk and dawn, to identify their peak attendance times, and to engage with the community and venue owners regarding the potential acceptability and feasibility of the venuebased study design.

In each HFCA, one focus group discussion (FGD) was held with community leaders ("headmen"). Additionally, one FGD was held with community health volunteers in the combined study area. All FGDs were conducted in the Siliozi language and followed a semi-structured guide. Participants were asked to discuss the types of venues that would be likely to meet a set of pre-defined venue eligibility criteria, to identify potential challenges to recruitment, and to develop a map of such venues and a list of peak attendance times. The venue eligibility criteria included that the venues be open at least once weekly between sundown and sunrise, have clientele mostly older than age 14 years, have a peak attendance of at least 10 people, have clientele deemed likely to be willing to participate, and that carrying out the study would not be expected to pose a risk to survey staff. Based on findings from the FGDs, a limited number of types of venues that appeared to have the largest number of venue-goers, greatest duration of time outdoors during mosquito-biting hours, and accessibility, were selected for inclusion in the survey. Formative study staff then visited the venues identified to confirm peak attendance times, request permission to conduct the study, and identify locations within or outside of each venue to conduct malaria testing and confidential interviews.

\section{Sampling and recruitment}

TLS was used to select venues and times to recruit survey participants. A sampling frame of VDTs was first constructed. VDTs were defined as 2- to 4-h intervals of peak attendance at a specific venue (e.g., Bar \#1 from 7 to $9 \mathrm{pm}$ on Fridays). At the start of each month, VDTs 
were randomly selected from the sampling frame and scheduled onto a calendar of recruitment events. As possible, four events (two per each of two field teams) were scheduled each Wednesday, Friday and Saturday (days when peak venue attendance was identified) during the approximately 10 -week data collection period. VDTs were selected by simple random sampling subject to logistical constraints: to limit travel time, a field team could travel to only one HFCA per evening; to limit burden on venue-goers, a venue could be visited no more than once weekly. An alternate VDT beginning on or after the start of each of these primary VDTs was also randomly selected, in case the primary venue was found to be closed, inaccessible, or had low attendance. Sampling quota were a minimum of 11 and a maximum of 25 participants per event, to meet a planned total sample size of 800 participants. The sample size was chosen to provide $80 \%$ power to detect a difference in polymerase chain reaction (PCR) parasite prevalence of 4 percentage points between households (anticipated to be $2 \%$ ) and venues (anticipated to be 6\%), assuming a design effect of 2 due to clustering by sampling event. Each month, the sampling frame was updated to reflect new venues or venue closures.

Field teams included an enumerator, a nurse and two interviewers. Enumerators designated an intercept line to count venue-goers present at any time during the event. When not conducting interviews, interviewers approached all venue-goers who crossed the line and verbally assessed eligibility.

Males and females ages 15 years and older who lived or worked in the Zambezi Region, had not participated previously and did not appear too intoxicated to provide informed consent were assessed for eligibility using a screening form and, if deemed eligible, invited to a confidential area outside and nearby the venue entrance. Those willing to provide written informed consent then completed a 15- to 30-minute interviewer-administered questionnaire via electronic tablet, which included demographics, outdoor activities between dusk and dawn, protective measures against mosquitos at the venue and place of sleeping, fever and malaria history, treatmentseeking for fever, and venue attendance patterns. The nurse then collected a finger-prick blood sample, conducted a malaria RDT and prepared a dried blood spot for molecular testing.

Participants with positive RDT results were provided free treatment on-site. Blood samples were frozen before being sent to a laboratory in Windhoek for loop-mediated isothermal amplification (LAMP), and follow-up PCR following all positive LAMP results, and on $10 \%$ of negatives. No monetary or other incentives were provided.
Participant ID codes linked questionnaires, specimens and test results. Names were not recorded. The study protocol was approved by The University of California, San Francisco Committee on Human Research, Institutional Review Board, the University of Namibia Research Ethics Committee, and the Research Management Committee of the Ministry of Health and Social Services of Namibia.

\section{Household survey}

Estimates of characteristics of the population reached by TLS were compared to results from a cross-sectional household survey covering the same geographic region and conducted between April and June, 2015. In this survey, 684 households were randomly sampled, 529 households enrolled, and 1918 household members interviewed and tested for malaria [11]. Sampling in the household survey was with probability proportional to number of households across HFCAs.

\section{Measures}

Responses to the following question were grouped to differentiate indoor and outdoor livelihood activities: "What are the occupations or activities that you do to support yourself and/or your family with income or food?". Outdoor activities were defined as agriculture or fishing (from responses subsistence agricultural worker, agricultural labourer, skilled agricultural or fishery worker, subsistence fishery worker, and small-scale fish vendor) and construction or security guard. Indoor activities were defined as professional, student or merchant (from responses teacher, student, professional, retail merchant, and other sales and services), domestic work ("homemaker") and "other" responses.

Respondents were asked about protective measures against malaria in their home including IRS and LLIN ownership, as well as whether they had been ill with fever anytime in the past 3 months, the last 2 weeks, and whether they sought treatment.

\section{Statistical analysis}

For categorical measures, proportions and 95\% confidence intervals (CIs) were estimated; medians and interquartile ranges were estimated for continuous measures. Differences by venue type were assessed using Wald tests. Differences between the TLS and household surveys were assessed using two-sample Z-tests.

Risk factors for malaria infection by RDT, PCR or LAMP could not be identified due to the small number of positives detected. Associations were identified between self-reported fever in the past 3 months using bivariate and multivariable logistic regression, examining variables related to demographics, potential 
exposure at the venue and at the place of sleeping. Response categories were combined in some cases where bivariate associations were similar. The multivariable model included all variables with bivariate associations at the $10 \%$ level. Analysis was conducted in Stata version 12.0 using procedures for complex surveys.

Estimates of prevalence and tests for associations from the TLS sample were weighted and standard errors were linearized to account for clustering by recruitment event [13-15]. Sampling weights were calculated as $\frac{1}{F_{e} A_{i}}$, where $F_{e}$ was the sampling fraction from respondent (i)'s sampling event and $A_{i}$ was the frequency of attendance, defined as the number of days the respondent went to the same type of venue (i.e., bars or churches) in the past 30 days between sundown and sunrise [16]. Frequency of attendance was imputed at the sample mean, by catchment area and venue type for $14(2.9 \%)$ participants due to non-response. A $5 \%$ trim was applied to the weights due to outliers ( $>3$ standard deviations from the mean). Differences at the $5 \%$ level were considered statistically significant.

\section{Results}

Identifying potentially high-risk venues

Several types of locations where individuals gathered between sundown and sunrise were identified during FGDs, including bars, churches, construction work sites, and cattle, fishing and police camps. The TLS study was limited to bars and churches as they were considered the most well-attended and accessible locations, often have windows or doors that are left open, and in some cases incomplete walls or open eaves. Twenty-one bars and four churches with evening hours were identified within the 6 catchment areas. VDTs, defined based on reported peak times, were generally between 3 and $8 \mathrm{pm}$ at churches and $6 \mathrm{pm}$ and 12am at bars. Selected HFCAs, venues, and households in the study area are shown in Fig. 1.

\section{TLS recruitment}

From March 27 to May 30, 2015, 480 study participants were recruited from 67 events held at 43 randomly selected VDTs, including 390 (81\%) participants at bars and $90(19 \%)$ at churches. Between 1 to 5 (median 3)

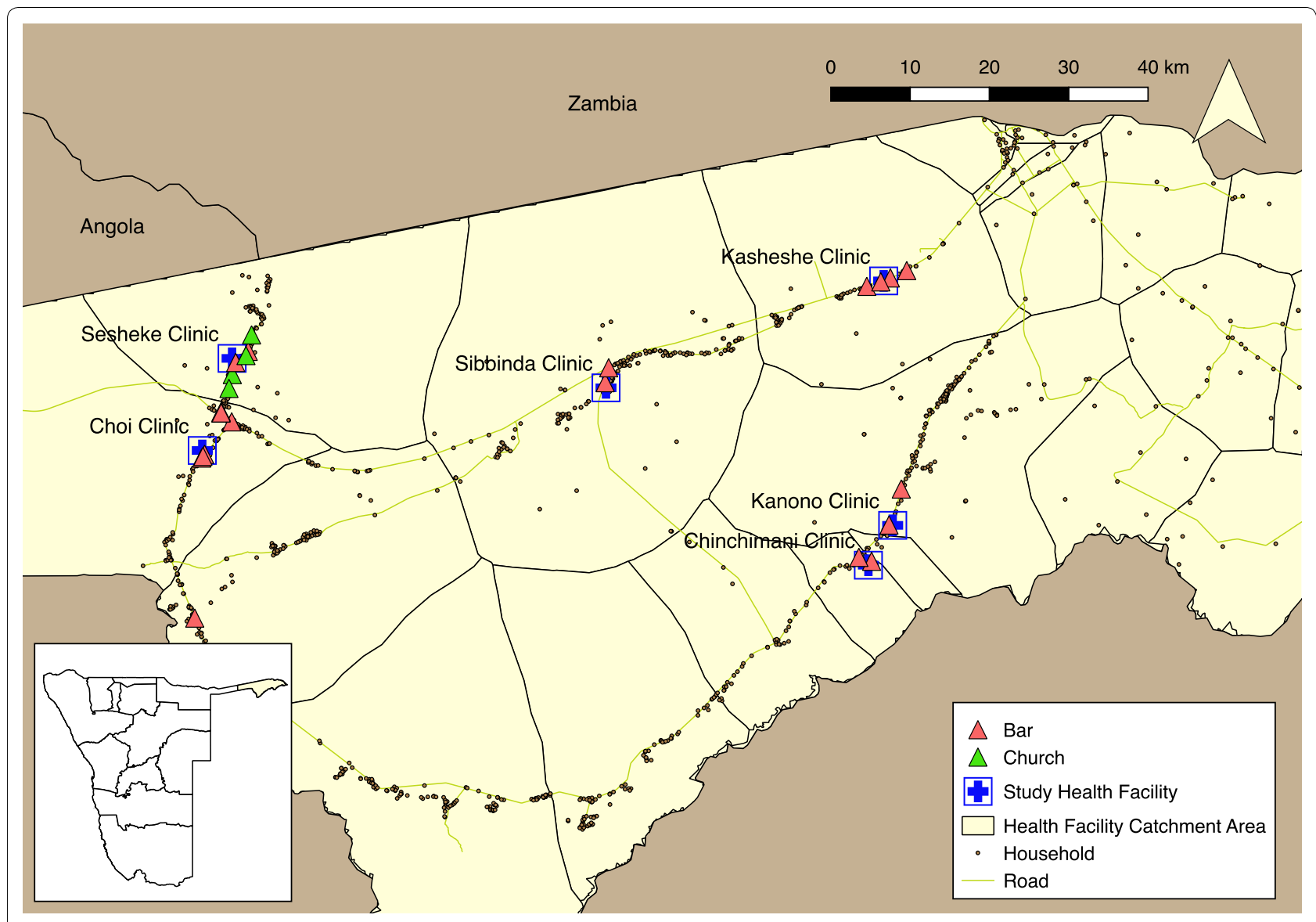

Fig. 1 Study area, Zambezi Region, Namibia, 2015 
sampling events were held per venue. Each venue contributed from $2(0.4 \%)$ to $45(9.4 \%)$ participants. Six additional events during the final month of data collection produced no new participants despite venue-goers in attendance. Of venue-goers approached, $80 \%$ at churches and $67 \%$ at bars were eligible and agreed to participate; this declined from $76 \%$ overall during the first 30 days to $51 \%$ during the latter half of the study period. The main reasons cited by field teams for non-participation were previous participation and lack of incentives.

\section{Demographics}

Based on weighted analysis, an estimated $62.8 \%$ of individuals frequenting bars and evening church services were male and $37.2 \%$ were female (Table 1 ). The median age was 25 years and $26.1 \%$ were 35 years or older. Most had completed primary education (79.0\%). Most venuegoers were Namibian citizens (97.9\%), while $1.4 \%$ were Zambian. About one quarter (27.5\%) worked in agriculture or fishing and 1 in $10(11.0 \%)$ in construction or as security guards; $37 \%$ earned income from any of these activities. Bar patrons were more likely to be younger (median 25 vs. 36 years; $P=0.001)$, male $(66.1 \%$ vs. $36.1 \% ; P=0.0281)$, and less likely to work in agriculture or fishing $(17.8 \%$ vs. $52.9 \% ; P=0.014)$ than church-goers.

\section{Exposure at venues}

Nearly a third (28.8\%) of participants frequented bars or churches between sundown and sunrise at least weekly. Most (79.3\%) spent more than $1 \mathrm{~h}$ during a typical visit to the venue where they were surveyed and $44.5 \%$ spent $3 \mathrm{~h}$ or more. About half (53.8\%) had been bothered by mosquitoes at the venue previously; $2.5 \%$ were using mosquito repellent at the time of the interview. These estimates of potential exposure to mosquito bites were similar at bars and churches.

\section{Exposure at place of sleeping}

About half (50.8\%) of venue-goers slept in structures the previous night where IRS had been conducted in the past year, $43.7 \%$ owned a mosquito net and $26.9 \%$ had slept under a net the previous night. Fifty participants (10.5\%) had slept outdoors in the past 2 weeks and 82 (17.3\%) had spent the night outside of their home village in the past 4 weeks. Of the 82 participants reporting overnight travel, 78 travelled within Namibia, 2 to Zambia and 2 did not report their destination. These estimates were also similar at bars and churches.

\section{Malaria infection, fever and treatment-seeking}

The estimated prevalence of malaria infection was $4.7 \%$ by LAMP and $0.5 \%$ by RDT, with no differences by type of venue. Of the 17 LAMP-positive participants, 13 were recruited from bars (11 males and 2 females) and 4 from churches (3 males and 1 female); LAMP-positive participants' ages ranged from 17 to 42 years (median 24 years) and were similar by sex and venue type. Only 2 of the 17 LAMP-positive participants tested positive by RDT. Two of the three RDT-positive participants tested positive by LAMP.

An estimated $52.1 \%$ of venue-goers had self-reported fever in the 2 weeks prior to the survey and $64.2 \%$ in the prior 3 months. Of the latter, 37.9\% (105) sought treatment or advice for the most recent fever episode. None of those who reported fever in the past 3 months reported receiving chloroquine or quinine: five received Coartem $^{\circledR}$; one received SP/Fansidar ${ }^{\circledR}$; 61 received Panadol ${ }^{\circledR}$; and 26 received other unspecified treatments. Of the six participants with fever in the past 3 months who took Coartem or SP/Fansidar anti-malarials at last fever, none tested positive for malaria by RDT, PCR or LAMP. Of the 88 who received other or no treatments, five $(5.7 \%)$ tested positive for malaria: two by RDT, one by PCR and five by LAMP; all five reported fever in the past 2 weeks.

Self-reported fever in the past 3 months was associated with engaging in livelihood activities that included agriculture, fishing, construction and security work $(\mathrm{OR}=1.7 ; P=0.030)$, ever being bothered by mosquitos at the venue $(\mathrm{OR}=2.8 ; P<0.001)$, not wearing personal protective measures when interviewed $(\mathrm{OR}=6.5$; $P=0.043)$, and Zambian citizenship $(\mathrm{OR}=12.4$; $P=0.009$ ) (Table 2). Malaria infection by LAMP was not significantly associated with self-reported fever in the past 2 weeks or 3 months $(P \geq 0.4)$.

\section{Venue-goers versus household population}

Relative to the household population aged 15 years and older, venue-goers were more likely to be male $(62.8 \%$ vs. $41.5 \% ; P<0.001)$, aged 15 to 24 years $(46.8 \%$ vs. $34.0 \%$; $P=0.013)$, and less likely to be age 45 years and older $(10.9 \%$ vs. $29.0 \%$; $P<0.001)$ (Table 3$)$. Venue-goers were more likely to have spent the night away from their home village in the past month $(17.3 \%$ vs. $8.9 \% ; P=0.008)$, to have experienced fever in the past 2 weeks $(52.1 \%$ vs. $33.2 \% ; P<0.001)$ and 3 months $(65.2 \%$ vs. $36.9 \%$; $P<0.001)$, less likely to have sought treatment at last fever (37.9\% vs. $52.1 \% ; P=0.011$ ), and moderately less likely to reside in a structure where IRS had been conducted in the past year $(50.8 \%$ vs. $60.0 \% ; P=0.063)$. Prevalence of malaria infection by LAMP between the venue-going population and the general population was not significantly different ( $4.7 \%$ vs. $2.8 \% ; P=0.740)$. Bar and church sub-samples both differed from the general population with respect to prevalence of fever and spending the night away from home; bar-goers differed from the general population with respect to age $(P<0.001)$, sex 
Table 1 Estimated characteristics of venue-goers, TLS survey, Zambezi Region, Namibia, 2015

\begin{tabular}{|c|c|c|c|c|c|c|c|c|c|}
\hline \multirow[t]{2}{*}{ Variables } & \multicolumn{3}{|c|}{$\begin{array}{l}\text { All venue-goers } \\
(\mathrm{N}=480)\end{array}$} & \multicolumn{3}{|c|}{$\begin{array}{l}\text { Bars } \\
(\mathrm{N}=390)\end{array}$} & \multicolumn{3}{|c|}{$\begin{array}{l}\text { Churches } \\
(\mathrm{N}=90)\end{array}$} \\
\hline & $\mathbf{N}$ & $\mathbf{n}$ & Percent $(95 \% \mathrm{Cl})$ & $\mathbf{N}$ & $\mathbf{n}$ & Percent $(95 \% \mathrm{CI})$ & $\mathbf{N}$ & $\mathrm{n}$ & Percent $(95 \% \mathrm{Cl})$ \\
\hline \multicolumn{10}{|l|}{ Demographics } \\
\hline \multicolumn{10}{|l|}{ Sex } \\
\hline Female & 480 & 155 & $37.2(28.0-47.3)$ & 390 & 105 & $33.9(24.0-45.5)$ & 90 & 50 & $63.9(49.2-76.5)$ \\
\hline Male & 480 & 325 & $62.8(52.7-72.0)$ & 390 & 285 & $66.1(54.5-76.0)$ & 90 & 40 & $36.1(23.5-50.8)$ \\
\hline \multicolumn{10}{|l|}{ Age } \\
\hline Median (IQR) & 480 & - & $25(20-36)$ & 390 & - & $25(20-34)$ & 90 & - & $36(23-50)$ \\
\hline $15-24$ & 480 & 202 & $46.8(37.1-56.7)$ & 390 & 176 & $49.1(38.7-59.5)$ & 90 & 26 & $27.7(13.7-48.1)$ \\
\hline $25-34$ & 480 & 133 & $27.1(21.2-34.0)$ & 390 & 116 & $28.3(21.8-35.8)$ & 90 & 17 & $17.7(9.8-29.7)$ \\
\hline $35-44$ & 480 & 77 & $15.2(10.5-21.5)$ & 390 & 61 & $14.1(9.3-20.9)$ & 90 & 16 & $24.1(14.6-37.3)$ \\
\hline $45+$ & 480 & 68 & $10.9(6.6-17.4)$ & 390 & 37 & $8.5(4.6-15.4)$ & 90 & 31 & $30.4(17.9-46.7)$ \\
\hline \multicolumn{10}{|l|}{ Education } \\
\hline Less than primary & 476 & 104 & $21.0(15.6-27.7)$ & 386 & 75 & $19.7(14.1-26.7)$ & 90 & 29 & $32.0(20.6-46.1)$ \\
\hline Primary & 476 & 212 & $43.7(35.6-52.2)$ & 386 & 179 & $43.8(35.0-53.0)$ & 90 & 33 & $42.8(24.4-63.4)$ \\
\hline Secondary or above & 476 & 160 & $35.3(28.0-43.2)$ & 386 & 132 & $36.5(28.4-45.3)$ & 90 & 28 & $25.2(16.5-36.3)$ \\
\hline \multicolumn{10}{|l|}{ Citizenship } \\
\hline Namibiana $^{a}$ & 480 & 462 & $97.9(95.7-99.0)$ & 390 & 376 & 98.5 (96.9-99.3) & 90 & 86 & $93.2(72.7-98.6)$ \\
\hline Zambian & 480 & 15 & $1.4(0.7-3.0)$ & 390 & 13 & $1.3(0.6-3.0)$ & 90 & 2 & $2.2(0.3-16.1)$ \\
\hline Other & 480 & 3 & $0.7(0.1-3.3)$ & 390 & 1 & $0.2(0.0-1.4)$ & 90 & 2 & $4.6(0.6-28.7)$ \\
\hline \multicolumn{10}{|l|}{ Livelihood activities } \\
\hline Agriculture/fishing & 480 & 174 & $27.5(20.0-36.5)$ & 390 & 123 & $23.3(16.4-31.9)$ & 90 & 51 & $62.5(42.7-78.9)$ \\
\hline Construction/security guard & 480 & 60 & $11.0(7.5-15.9)$ & 390 & 54 & $11.8(7.9-17.3)$ & 90 & 6 & $4.3(1.3-13.0)$ \\
\hline Professional/student/merchant & 480 & 189 & $40.5(33.1-48.4)$ & 390 & 157 & $41.7(33.9-49.9)$ & 90 & 32 & $31.3(15.2-53.7)$ \\
\hline Homemaker/other & 480 & 97 & $15.7(10.8-22.3)$ & 390 & 85 & $16.3(10.9-23.7)$ & 90 & 12 & $10.5(3.8-25.6)$ \\
\hline Agriculture, fishing, construction or security guard & 480 & 219 & $37.0(28.5-46.3)$ & 390 & 164 & $33.7(25.5-43.1)$ & 90 & 55 & $64.1(44.1-80.2)$ \\
\hline \multicolumn{10}{|l|}{ Venue } \\
\hline $\begin{array}{l}\text { Attends this type of venue (bar or church) between sun- } \\
\text { down and sunrise at least weekly }\end{array}$ & 466 & 294 & $28.8(21.2-37.8)$ & 383 & 245 & $28.5(20.2-38.4)$ & 83 & 49 & $31.4(19.1-47.2)$ \\
\hline \multicolumn{10}{|l|}{ Duration of typical visit to venue } \\
\hline$<1 \mathrm{~h}$ & 469 & 73 & $20.7(14.7-28.3)$ & 383 & 60 & $20.4(14.1-28.6)$ & 86 & 13 & $23.1(9.3-46.7)$ \\
\hline $1-2 \mathrm{~h}$ & 469 & 155 & $34.8(25.6-45.4)$ & 383 & 125 & $33.9(24.1-45.5)$ & 86 & 30 & $42.1(22.5-64.7)$ \\
\hline$\geq 3 h$ & 469 & 241 & $44.5(35.0-54.3)$ & 383 & 198 & $45.7(35.5-56.2)$ & 86 & 43 & $34.7(19.8-53.5)$ \\
\hline Ever bothered by mosquitos at venue & 478 & 281 & $53.8(44.7-62.7)$ & 389 & 229 & $53.3(43.2-63.1)$ & 89 & 52 & $57.8(46.3-68.5)$ \\
\hline $\begin{array}{l}\text { Personal protective measures against malaria at time of } \\
\text { survey }\end{array}$ & 478 & 10 & $2.5(0.9-6.3)$ & 388 & 9 & $2.7(1.0-7.1)$ & 90 & 1 & $0.5(0.1-3.5)$ \\
\hline \multicolumn{10}{|l|}{ Place of sleeping } \\
\hline \multicolumn{10}{|l|}{ Last time IRS in structure where sleeps } \\
\hline$<1$ year & 361 & 173 & $50.8(43.0-58.6)$ & 284 & 124 & $48.9(40.5-57.2)$ & 77 & 49 & $63.7(48.2-76.8)$ \\
\hline$\geq 1$ year & 361 & 83 & $19.8(14.5-26.4)$ & 284 & 70 & $20.3(14.5-27.7)$ & 77 & 13 & $16.5(8.2-30.5)$ \\
\hline Never & 361 & 105 & $29.4(22.0-38.0)$ & 284 & 90 & $30.8(22.9-40.0)$ & 77 & 15 & $19.8(6.9-45.0)$ \\
\hline Owns a mosquito net & 480 & 204 & $43.7(36.1-51.6)$ & 390 & 166 & $44.6(36.2-53.3)$ & 90 & 38 & $35.8(27.1-45.6)$ \\
\hline Slept under a net last night & 479 & 135 & $26.9(20.3-34.8)$ & 389 & 106 & $27.1(19.8-36.0)$ & 90 & 29 & $25.2(18.8-33.0)$ \\
\hline Slept outdoors in past 2 weeks & 479 & 50 & $10.5(7.1-15.3)$ & 389 & 38 & $10.6(6.9-15.9)$ & 90 & 12 & $10.2(5.0-19.8)$ \\
\hline Spent the night outside of home village in past 4 weeks & 479 & 82 & $17.3(12.6-23.3)$ & 389 & 65 & $17.0(11.9-23.7)$ & 90 & 17 & $20.0(12.2-30.9)$ \\
\hline \multicolumn{10}{|l|}{ Fever } \\
\hline Past 2 weeks & 478 & 245 & $52.1(45.8-58.3)$ & 388 & 191 & $50.4(43.9-56.9)$ & 90 & 54 & $65.7(49.6-78.9)$ \\
\hline Past 3 months & 478 & 300 & $65.2(59.2-70.8)$ & 388 & 238 & $64.2(57.7-70.2)$ & 90 & 62 & $73.4(59.2-83.9)$ \\
\hline Sought treatment last time ${ }^{b}$ & 299 & 105 & $37.9(28.9-47.8)$ & 237 & 79 & $36.8(27.0-47.8)$ & 62 & 26 & $45.7(28.8-63.6)$ \\
\hline
\end{tabular}


Table 1 (continued)

\begin{tabular}{|c|c|c|c|c|c|c|c|c|c|}
\hline \multirow[t]{2}{*}{ Variables } & \multicolumn{3}{|c|}{$\begin{array}{l}\text { All venue-goers } \\
(\mathrm{N}=480)\end{array}$} & \multicolumn{3}{|c|}{$\begin{array}{l}\text { Bars } \\
(\mathrm{N}=390)\end{array}$} & \multicolumn{3}{|c|}{$\begin{array}{l}\text { Churches } \\
(\mathrm{N}=90)\end{array}$} \\
\hline & $\mathrm{N}$ & $n$ & Percent $(95 \% \mathrm{CI})$ & $\mathrm{N}$ & $\mathrm{n}$ & Percent $(95 \% \mathrm{Cl})$ & $\mathrm{N}$ & $n$ & Percent $(95 \% \mathrm{Cl}$ \\
\hline \multicolumn{10}{|c|}{ Treatment received last time ${ }^{c}$} \\
\hline Coartem & 94 & 5 & $3.4(3.4-3.4)$ & 68 & 4 & $3.8(3.8-3.8)$ & 26 & 1 & $1.3(0.2-9.6)$ \\
\hline SP/Fansidar & 94 & 1 & $0.3(0.3-0.3)$ & 68 & 0 & 0.0 & 26 & 1 & $1.5(0.2-10.2)$ \\
\hline Panadol & 94 & 61 & $69.2(69.2-69.2)$ & 68 & 44 & $68.5(68.5-68.5)$ & 26 & 17 & $72.1(51.0-86.5)$ \\
\hline Other & 94 & 26 & $26.6(26.6-26.6)$ & 68 & 19 & $26.9(26.9-26.9)$ & 26 & 7 & $25.1(10.8-47.9)$ \\
\hline None & 94 & 1 & $0.7(0.7-0.7)$ & 68 & 1 & $0.8(0.8-0.8)$ & 26 & 0 & - \\
\hline \multicolumn{10}{|l|}{ Malaria infection } \\
\hline RDT reactive & 479 & 3 & $0.5(0.1-3.6)$ & 389 & 1 & $0.0(0.0-0.2)$ & 90 & 2 & $4.6(0.6-28.7)$ \\
\hline PCR reactive & 479 & 7 & $1.6(0.5-4.7)$ & 389 & 6 & $1.6(0.5-5.2)$ & 90 & 1 & $1.4(0.2-11.1)$ \\
\hline LAMP reactive & 480 & 17 & $4.7(2.4-8.9)$ & 390 & 13 & $4.3(2.0-9.0)$ & 90 & 4 & $7.8(2.1-25.1)$ \\
\hline
\end{tabular}

$(P<0.001)$, IRS in past year $(P=0.031)$, and treatmentseeking for fever $(P=0.011)$ (Fig. 2).

\section{Discussion}

In a low-transmission setting on the path to malaria elimination, community members identified types of locations where individuals gather away from their homes during late afternoon and evening mosquito-biting hours. Active surveillance was conducted at what appeared to be the most numerous and accessible venues for malaria surveillance-bars and churches with late afternoon and evening services-during randomly selected peak-attendance days and times. TLS proved a feasible and acceptable strategy to determine the prevalence of malaria infection, activities that may increase exposure, and use of personal protective measures among patrons of these venues.

This study was motivated by the hypothesis that partially outdoor locations where individuals gather during mosquito-biting hours may contribute to ongoing transmission in the western Zambezi region, yet findings on this point were mixed. While malaria prevalence among venue-goers was nearly twice that among the general population aged 15 years and older as assessed by a household survey, the difference was not statistically significant. Because the study did not reach its planned sample size, the lack of significance may be due to limited statistical power. If this is the case and venue patrons are truly at greater risk, then this study offers a number of explanations.

First, there is some evidence venue attendance itself may be a source of risk. Malaria rates were non-significantly higher at both bars and churches, compared to the general population, suggesting a common pattern. Most venue-goers had been bothered by mosquitoes while attending both types of venues, while few used protective measures. Both of these characteristics were associated with self-reported fever. Rates of fever were significantly greater compared to the general population and venue-goers were less likely to seek advice or treatment when experiencing fever, suggesting they could potentially transmit to peers over a longer period, including other venue-goers, compared to non-venue-goers. Recent evidence suggests alcohol consumption may attract anophelene mosquitoes [17], so that bar patrons may be at greater risk of potentially infectious bites. Yet, much of this evidence is tenuous: the study did not verify self-reported fever nor determine how participants assessed fever, so that this measure could merely reflect "feeling hot" or be due to other unspecified viral or bacterial causes, particularly given the low level of malaria transmission during the study period. Because entomological data were not collected around venues, the transmission potential of mosquitoes present could not be assessed.

A second explanation, more strongly supported by our data, is that the venues attract individuals who were otherwise at greater risk. Bar patrons were more likely to be male and aged 15-24, while patrons of both types of venues were more likely to engage in overnight travel outside of their community than the general population, characteristics which have been identified as risk factors for malaria elsewhere in northern Namibia [15]. Many venue-goers, principally evening church patrons, also 
Table 2 Factors associated with fever in past 3 months, TLS survey, Zambezi Region, Namibia

\begin{tabular}{llll}
\hline Variables & $\begin{array}{l}\text { Fever } \\
\text { in past 3 months }\end{array}$ & Bivariate & $\begin{array}{l}\text { Multivariable } \\
(\mathrm{N}=474)\end{array}$ \\
\cline { 2 - 3 } & OR $(95 \% \mathrm{Cl})$ & AOR $(95 \% \mathrm{Cl})$
\end{tabular}

Demographics

Sex

\begin{tabular}{|c|c|c|c|c|}
\hline Female & 100 & 68.0 & \multicolumn{2}{|l|}{1.0} \\
\hline Male & 200 & 63.6 & \multicolumn{2}{|l|}{$0.8(0.4-1.6)$} \\
\hline \multicolumn{5}{|l|}{ Age } \\
\hline $15-24$ & 125 & 69.6 & \multicolumn{2}{|l|}{1.0} \\
\hline $25-34$ & 88 & 66.6 & \multicolumn{2}{|l|}{$0.9(0.5-1.6)$} \\
\hline $35-44$ & 45 & 51.9 & \multicolumn{2}{|l|}{$0.5(0.2-1.0)$} \\
\hline $45+$ & 42 & 61.5 & \multicolumn{2}{|l|}{$0.7(0.3-1.7)$} \\
\hline \multicolumn{5}{|l|}{ Education } \\
\hline $\begin{array}{l}\text { Primary or } \\
\text { above }\end{array}$ & 229 & 63.4 & \multicolumn{2}{|l|}{1.0} \\
\hline $\begin{array}{l}\text { Less than } \\
\text { primary }\end{array}$ & 71 & 72.1 & \multicolumn{2}{|l|}{$1.5(0.6-3.5)$} \\
\hline \multicolumn{5}{|l|}{ Citizenship } \\
\hline Namibian & 284 & 64.6 & 1.0 & 1.0 \\
\hline Zambian & 16 & 95.8 & $12.4(2.1-71.2)$ & $12.2(1.6-91.7)$ \\
\hline \multicolumn{5}{|c|}{$\begin{array}{l}\text { Livelihood activities include agriculture, fishing, construction, or } \\
\text { security guard }\end{array}$} \\
\hline No & 152 & 60.0 & 1.0 & 1.0 \\
\hline Yes & 148 & 74.3 & $1.7(0.9-3.3)$ & $1.9(1.0-3.3)$ \\
\hline
\end{tabular}

Venue

Attends this type of venue (bar o church) between sundown and sunrise at least weekly

$\begin{array}{llll}\text { No } & 107 & 63.8 & 1.0 \\ \text { Yes } & 184 & 68.6 & 1.2(0.8-2.0)\end{array}$

Duration of typical visit to venue

$\begin{array}{lrrl}<1 \mathrm{~h} & 43 & 66.7 & 1.0 \\ 1-2 \mathrm{~h} & 108 & 74.8 & 1.5(0.6-3.7) \\ \geq 3 \mathrm{~h} & 145 & 58.7 & 0.7(0.3-1.5)\end{array}$

Ever bothered by mosquitos at venue

$\begin{array}{lrrll}\text { No } & 97 & 52.7 & 1.0 & 1.0 \\ \text { Yes } & 202 & 75.9 & 2.8(1.7-4.8) & 2.7(1.5-4.6)\end{array}$

Wearing mosquito repellent, cream or spray at time of survey

$\begin{array}{lrlll}\text { Yes } & 5 & 23.2 & 1.0 & 1.0 \\ \text { No } & 295 & 66.4 & 6.5(1.1-40.4) & 6.8(1.4-33.6)\end{array}$

Place of sleeping

Last time IRS in structure where sleeps

$$
\begin{array}{lrrl}
<1 \text { year } & 109 & 64.3 & 1.0 \\
\geq 1 \text { year } & 56 & 65.0 & 1.0(0.5-2.1)
\end{array}
$$$$
\text { Never } \quad 71 \quad 66.7 \quad 1.1(0.5-2.3)
$$

Slept outdoors in past 2 weeks

$$
\begin{array}{lrrl}
\text { No } & 264 & 65.1 & 1.0 \\
\text { Yes } & 35 & 65.9 & 1.0(0.3-3.6)
\end{array}
$$

\begin{tabular}{|c|c|c|c|c|}
\hline \multirow[t]{2}{*}{ Variables } & \multicolumn{2}{|c|}{$\begin{array}{l}\text { Fever } \\
\text { in past } 3 \text { months }\end{array}$} & \multirow{2}{*}{$\begin{array}{l}\text { Bivariate } \\
\text { OR }(95 \% \mathrm{Cl})\end{array}$} & \multirow{2}{*}{$\begin{array}{l}\text { Multivariable } \\
(\mathrm{N}=474) \\
\text { AOR }(95 \% \mathrm{Cl})\end{array}$} \\
\hline & $\mathrm{n}$ & Percent & & \\
\hline \multicolumn{5}{|c|}{ Slept under a net last night } \\
\hline No & 222 & 64.9 & 1.0 & \\
\hline Yes & 78 & 66.3 & $1.1(0.5-2.4)$ & \\
\hline \multicolumn{5}{|c|}{ Spent the night outside of home village in past 4 weeks } \\
\hline No & 247 & 63.9 & 1.0 & \\
\hline Yes & 52 & 71.6 & $1.4(0.6-3.3)$ & \\
\hline
\end{tabular}

Owns a mosquito net

\begin{tabular}{llll} 
No & 180 & 68.9 & 1.0 \\
Yes & 120 & 60.4 & $0.7(0.4-1.3)$ \\
\hline
\end{tabular}

Table 2 (continued)

OR Odds ratio, $A O R$ unadjusted odds ratio, $C l$ confidence interval, IRS indoor residual spraying

AORs significant at the $5 \%$ level are in italic

engage in livelihood activities that are primarily outdoors and therefore may increase exposure.

A third, related explanation is that evening venue attendance may reflect a tendency to be outdoors at night generally. Venue attendance, together with the low observed levels of protective measures, may also reflect less concern about mosquito bite exposure, however such attitudes were not measured directly. Together, study findings point to a population marked by a number of risk factors without offering definitive evidence of sources of risk.

The finding of greater self-reported fever among Zambians relative to other venue-goers is consistent with evidence from an earlier case-control study linking malaria to travel to Namibia's northern border [18]. Greater cross-border interventions are needed, including targeted prevention and surveillance and improved coordination to ensure access to prevention information, and timely testing and treatment for individuals in Namibia who travel to Zambia and Angola.

The findings have other important limitations. Other types of venues, such as construction and agricultural work sites (identified in the formative research but not included in this study), could be associated with malaria risk and should be examined by future research. Due to time constraints, rates of venue attendance were not assessed by direct observation ahead of the study in order to inform the sampling plan; this may have contributed in part to failure to meet sample size targets [19]. There was considerable non-response on the household IRS measure, which was more common among younger respondents $\left(X^{2} P=0.002\right)$, suggesting that youth may not be able to provide information needed to characterize malaria risk at their residence. It was not possible to assess the degree of bias in prevalence estimates due to potentially greater participation by individuals who may have been motivated to obtain free malaria testing because they 
Table 3 Comparison of estimates from TLS and household surveys, Zambezi Region, Namibia, 2015

\begin{tabular}{|c|c|c|c|c|c|c|c|}
\hline \multirow[t]{2}{*}{ Variables } & \multicolumn{3}{|c|}{$\begin{array}{l}\text { TLS survey } \\
(\mathrm{N}=480)\end{array}$} & \multicolumn{3}{|c|}{$\begin{array}{l}\text { Household survey } \\
(\mathrm{N}=1160)\end{array}$} & \multirow[t]{2}{*}{ P-value } \\
\hline & $\mathrm{N}$ & Percent & SE & $\mathrm{N}$ & Percent & SE & \\
\hline \multicolumn{8}{|l|}{ Demographics } \\
\hline \multicolumn{8}{|l|}{ Sex } \\
\hline Female & 480 & 37.2 & 0.049 & 1160 & 58.5 & 0.019 & $<0.001$ \\
\hline Male & 480 & 62.8 & 0.049 & 1160 & 41.5 & 0.019 & $<0.001$ \\
\hline \multicolumn{8}{|l|}{ Age } \\
\hline $15-24$ & 480 & 46.8 & 0.050 & 1160 & 34.0 & 0.014 & 0.013 \\
\hline $25-34$ & 480 & 27.1 & 0.032 & 1160 & 21.9 & 0.015 & 0.140 \\
\hline $35-44$ & 480 & 15.2 & 0.027 & 1160 & 15.2 & 0.008 & 1.00 \\
\hline $45+$ & 480 & 10.9 & 0.027 & 1160 & 29.0 & 0.019 & $<0.001$ \\
\hline \multicolumn{8}{|l|}{ Place of sleeping } \\
\hline IRS in structure where sleeps in $<1$ year & 361 & 50.8 & 0.039 & $505^{\mathrm{a}}$ & 60.0 & 0.030 & 0.063 \\
\hline Slept outdoors in past 2 weeks & 479 & 10.5 & 0.020 & 1158 & 10.7 & 0.034 & 0.962 \\
\hline Owns a mosquito net & 480 & 43.7 & 0.039 & NA & NA & NA & NA \\
\hline Slept under net last night & 479 & 26.9 & 0.036 & 1154 & 34.5 & 0.036 & 0.140 \\
\hline $\begin{array}{l}\text { Spent the night outside of home village in } \\
\text { past } 4 \text { weeks }\end{array}$ & 479 & 17.3 & 0.027 & 1160 & 8.9 & 0.017 & 0.008 \\
\hline \multicolumn{8}{|l|}{ Fever } \\
\hline Past 2 weeks & 478 & 52.1 & 0.032 & 1151 & 33.2 & 0.030 & $<0.001$ \\
\hline Past 3 months & 478 & 65.2 & 0.029 & 1153 & 36.9 & 0.037 & $<0.001$ \\
\hline Sought treatment last time ${ }^{b}$ & 299 & 37.9 & 0.048 & 422 & 52.1 & 0.029 & 0.011 \\
\hline Received treatment last time ${ }^{b}$ & 288 & 33.9 & 0.047 & 422 & 38.6 & 0.492 & 0.924 \\
\hline Malaria infection (LAMP) & 480 & 4.7 & 0.015 & 1064 & 2.8 & 0.055 & 0.740 \\
\hline
\end{tabular}

$\mathrm{SE}$, standard error; LAMP, loop-mediated isothermal amplification. P-value for differences significant at the $5 \%$ are in italic

a Variable reported by household heads only $(\mathrm{N}=505)$

b Among those with fever in past 3 months

were ill; future venue-based studies should record reasons for participation and refusal.

TLS was developed in the context of HIV in urban settings dense with venues and venue-goers $[6,7]$, whereas transmission in malaria elimination settings tends to occur in rural, poor, low-population areas. This presents a challenge for reaching the planned sample size; future TLS surveillance should consider longer data collection periods and expanding the study area to compensate.

\section{Conclusion}

In the global push to eliminate malaria, many countries have identified high-risk populations that play an important role in sustaining transmission yet are not easily reached by conventional surveillance and control strategies [5]. The present study suggests that in a region of continuing malaria transmission in Namibia, targeted prevention at night-time venues offers a strategy complementary to the largely household-based strategies in place, such as widespread provision of LLINs, IRS and strengthening diagnostic capacity at health services. Bars and evening churches provide efficient access to individuals who tend to be out at night and are characterized by several known risk factors. Importantly, they also provide more efficient access to young males (at bars) and overnight travelers (at bars and churches) than household surveys, and to individuals who also may be missed by passive surveillance, as they are less likely to present to clinics when ill relative to the general population.

Strategies that should be considered at these sites include providing information on malaria prevention and testing, providing on-site testing and treatment, and distributing LLINs. Additional research is needed to clarify which venues actually play a role in transmission, in order to prioritize venue-focused interventions such as IRS. Such research should include gathering vector data around suspected venues, conducting TLS during a greater portion of malaria season in order to increase 


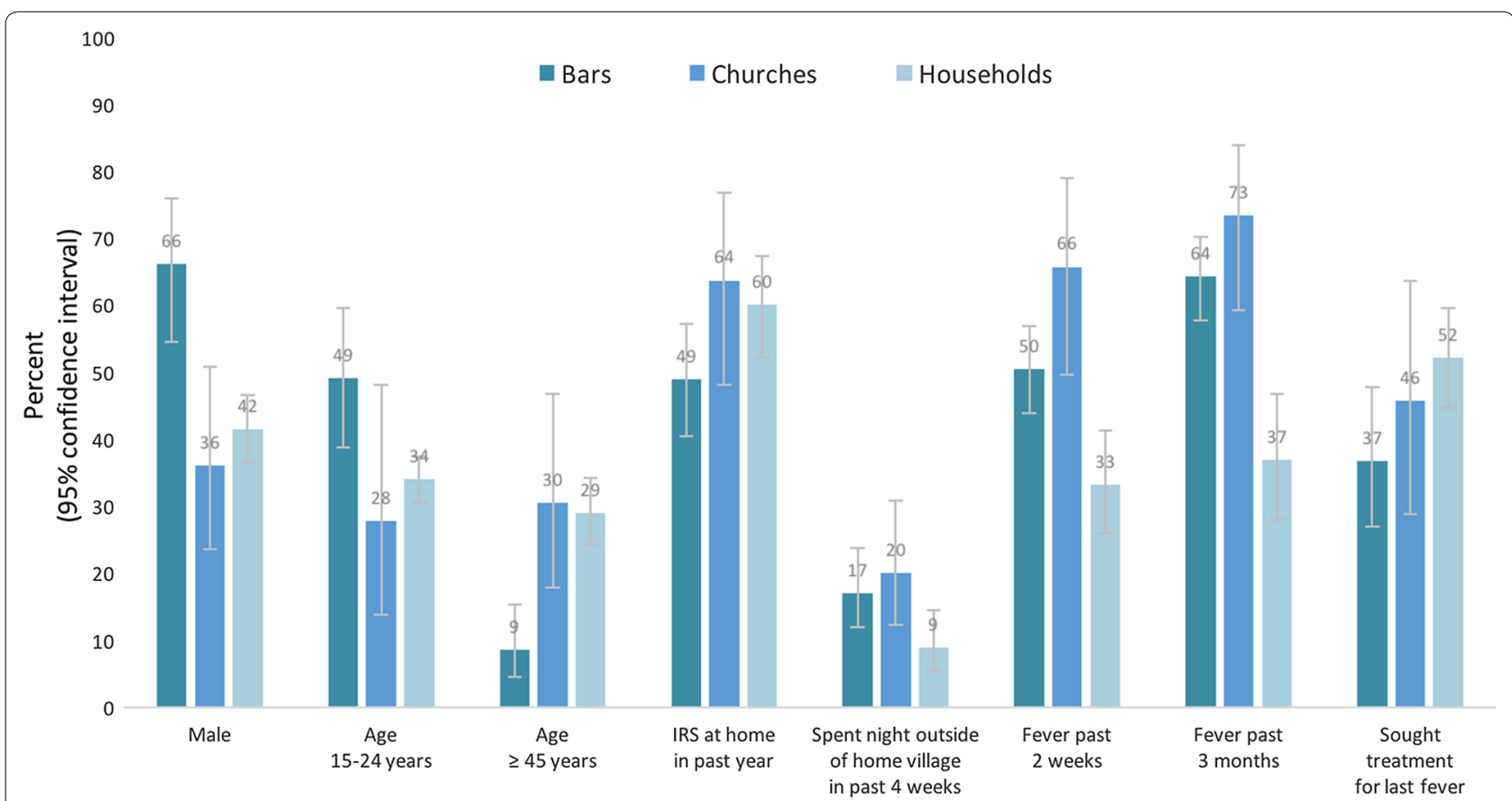

Fig. 2 Variables with significant differences detected between TLS and household surveys, Zambezi Region, Namibia, 2015. Sample sizes were 390 (Bars), 90 (Churches), and 1160 (Households) with some non-response for specific variables (see Tables 1 and 3)

power to detect elevated risk, and including questions about venue attendance in malaria indicator surveys.

While individuals who engage in outdoor social and occupational activities are increasingly seen as a target for onsite testing and treatment [3, 4, 20], improvements in the limited diagnostic value of RDTs are required to enhance the effectiveness and cost-effectiveness of such interventions.

\section{Acknowledgements}

We are grateful to the residents of Zambezi region for their help and cooperation with the study, the national and regional Ministry of Health and Social Services, and the local traditional leadership for their support.

\section{Authors' contributions}

$\mathrm{JJ}$ and $\mathrm{AB}$ led the conception and study design. DM, JS, RG, CC, KR, and MSH contributed to the study design. CC, MC, KR, DM, JS, JJ supported study implementation, data collection, and laboratory testing. JJ and CC performed data cleaning and data analyses. JJ, JS, CC, RG, and AB wrote the manuscript. All authors read and approved the final manuscript.

\section{Funding}

This work was supported by a Grant from the Bill and Melinda Gates Foundation (Grant No. A122394).

\section{Availability of data and materials}

The dataset supporting the conclusions of this article can be requested from the Namibia Ministry of Health and Social Services.

\section{Ethics approval and consent to participate}

Institutional Review Board approval for this study was obtained from the University of California San Francisco, the University of Namibia, and the Ministry of Health and Social Services of Namibia. Written consent by signature or finger print was provided from all consenting participants.

\section{Consent for publication}

Not applicable.

\section{Competing interests}

The authors declare that they have no competing interests.

\section{Author details}

${ }^{1}$ Malaria Elimination Initiative, Global Health Group, University of California, San Francisco, 550 16th St., San Francisco, CA 94158, USA. ${ }^{2}$ Multidisciplinary Research Center, University of Namibia, Windhoek, Namibia. ${ }^{3}$ Department of Pediatrics, Benioff Children's Hospital, University of California San Francisco, San Francisco, CA, USA. ${ }^{4}$ Department of Pediatrics, University of Texas Southwestern Medical Center, Dallas, TX, USA.

Received: 8 February 2019 Accepted: 10 May 2019

Published online: 22 May 2019

\section{References}

1. Chanda E, Ameneshewa B, Angula HA, litula I, Uusiku P, Trune D, et al. Strengthening tactical planning and operational frameworks for vector control: the roadmap for malaria elimination in Namibia. Malar J. 2015;14:302.

2. Smith Gueye C, Gerigk M, Newby G, Lourenco C, Uusiku P, Liu J. Namibia's path toward malaria elimination: a case study of malaria strategies and costs along the northern border. BMC Public Health. 2014;14:1190.

3. Cooke MK, Kahindi SC, Oriango RM, Owaga C, Ayoma E, Mabuka D, et al. A bite before bed: exposure to malaria vectors outside the times of net use in the highlands of western Kenya. Malar J. 2015;14:259.

4. Monroe A, Asamoah O, Lam Y, Koenker H, Psychas P, Lynch M, et al. Outdoor-sleeping and other night-time activities in northern Ghana: 
implications for residual transmission and malaria prevention. Malar J. 2015;14:35

5. Jacobson JO, Cueto C, Smith JL, Hwang J, Gosling R, Bennett A. Surveillance and response for high-risk populations: what can malaria elimination programmes learn from the experience of HIV? Malar J. 2017;16:33.

6. MacKellar D, Valleroy L, Karon J, Lemp G, Janssen R. The Young Men's Survey: methods for estimating HIV seroprevalence and risk factors among young men who have sex with men. Public Health Rep. 1996;111(Suppl 1):138-44. https://www.pubmedcentral.nih.gov/articlerender.fcgi?artid $=1382056 \&$ tool $=$ pmcentrez\&rendertype $=$ abstract.

7. Muhib FB, Lin LS, Stueve A, Miller RL, Ford WL, Johnson P, et al. A venuebased method for sampling hard-to-reach populations. Public Health Rep. 2001;116(Suppl 1):216-22.

8. UNAIDS, WHO. Guidelines on surveillance among populations most at risk for HIV. Geneva: World Health Organization; 2011.

9. Schicker RS, Hiruy N, Melak B, Gelaye W, Bezabih B, Stephenson R, et al. A venue-based survey of malaria, anemia and mobility patterns among migrant farm workers in Amhara Region Ethiopia. PLoS ONE. 2015;10:e0143829.

10. Namibia Statistics Agency. Namibia 2011 population and housing census [PUMS Datdata]. Version 1.0. Windhoek, Namibia; 2011.

11. McCreesh P, Mumbengegwi D, Roberts K, Tambo M, Smith J, Whittemore $B$, et al. Subpatent malaria in a low transmission African setting: a crosssectional study using rapid diagnostic testing (RDT) and loop-mediated isothermal amplification (LAMP) from Zambezi region Namibia. Malar J. 2018;17:480.

12. Cueto C, Jacobson J, Smith J, Mumbengegwi D, Sturrock H, Gosling R. Active surveillance through peer referral to identify populations at higher risk for malaria in Zambezi region. Namibia. Am J Trop Med Hyg. 2015;93:472-3.

13. Froot KA. Consistent covariance matrix estimation with cross-sectional dependence and heteroskedasticity in financial data. J Financ Quant Anal. 1989;24:333-55.

14. Rogers WH. Regression standard errors in clustered samples. Stata Technical Bull. 1993;3:88-94.

15. Williams RL. A note on robust variance estimation for cluster-correlated data. Biometrics. 2000;56:645-6.

16. Karon $\mathrm{JM}$, Wejnert C. Statistical methods for the analysis of time-location sampling data. J Urban Health. 2012;89:565-86.

17. Dabire KR, Costantini C. Beer consumption increases human attractiveness to malaria mosquitoes. PLoS ONE. 2010;5:e9546.

18. Smith JL, Auala J, Haindongo E, Uusiku P, Rosling R, Kleinschmidt I, et al. Malaria risk in young male travellers but local transmission persists: a case-control study in low transmission Namibia. Malar J. 2017;16:70.

19. Raymond HF, Ick T, Grasso M, Vaudrey J, McFarland W. Resource guide : time location sampling (TLS). 2nd Edn. San Francisco Department of Public Health, 2007.

20. Vajda É, Webb C. Assessing the risk factors associated with malaria in the Highlands of Ethiopia: what do we need to know? Trop Med Infect Dis. 2017:2:4

\section{Publisher's Note}

Springer Nature remains neutral with regard to jurisdictional claims in published maps and institutional affiliations.
Ready to submit your research? Choose BMC and benefit from:

- fast, convenient online submission

- thorough peer review by experienced researchers in your field

- rapid publication on acceptance

- support for research data, including large and complex data types

- gold Open Access which fosters wider collaboration and increased citations

- maximum visibility for your research: over $100 \mathrm{M}$ website views per year

At $\mathrm{BMC}$, research is always in progress.

Learn more biomedcentral.com/submissions 